Article

\title{
Development and Application of Electrochemical Sensor Based on Molecularly Imprinted Polymer and Carbon Nanotubes for the Determination of Carvedilol
}

\author{
Malena Karla Lombello Coelho ${ }^{1}$, Juliana de Fátima Giarola ${ }^{1}$, Anny Talita Maria da Silva ${ }^{1}$, \\ César Ricardo Teixeira Tarley ${ }^{2,3}$, Keyller Bastos Borges ${ }^{1}$ and Arnaldo César Pereira ${ }^{1, *}$ \\ 1 Departamento de Ciências Naturais, Universidade Federal de São João del Rei (UFSJ), Campus Dom Bosco, \\ Praça Dom Helvécio 74, Fábricas 36301-160, São João del Rei, MG, Brazil; malenoka@gmail.com (M.K.L.C.); \\ juhgiarola@hotmail.com (J.F.G.); annytalita@hotmail.com (A.T.M.S.); keyller@ufsj.edu.br (K.B.B.) \\ 2 Departamento de Química, Universidade Estadual de Londrina (UEL), Rod. Celso Garcia Cid, \\ PR 445 Km 380, Campus Universitário, Londrina, PR, CEP 86051-990, Brazil; ctarleyquim@yahoo.com.br \\ 3 Instituto Nacional de Ciência e Tecnologia (INCT) de Bioanalítica, Universidade Estadual de Campinas \\ (UNICAMP), Instituto de Química, Departamento de Química Analítica, Cidade Universitária Zeferino Vaz \\ s/n, CEP 13083-970, Campinas, SP, Brazil \\ * Correspondence: arnaldocsp@yahoo.com.br; Tel.: +55-32-3379-2478
}

Academic Editor: Peter Lieberzeit

Received: 5 August 2016; Accepted: 11 November 2016; Published: 27 November 2016

\begin{abstract}
This work describes the preparation of a glassy carbon electrode (GCE) modified with molecularly imprinted polymer (MIP) and multiwalled carbon nanotubes (MWCNTs) for determination of carvedilol (CAR). Electrochemical behavior of CAR on the modified electrode was evaluated using cyclic voltammetry. The best composition was found to be $65 \%(\mathrm{~m} / \mathrm{m})$ of MIP. Under optimized conditions ( $\mathrm{pH} 8.5 \mathrm{in} 0.25 \mathrm{~mol} \cdot \mathrm{L}^{-1}$ Britton-Robinson buffer and $0.1 \mathrm{~mol} \cdot \mathrm{L}^{-1} \mathrm{KCl}$ ) the voltammetric method showed a linear response for CAR in the range of 50-325 $\mu \mathrm{mol} \cdot \mathrm{L}^{-1}$ $(\mathrm{R}=0.9755)$, with detection and quantification limits of $16.14 \mu \mathrm{mol} \cdot \mathrm{L}^{-1}$ and $53.8 \mu \mathrm{mol} \cdot \mathrm{L}^{-1}$, respectively. The developed method was successfully applied for determination of CAR in real samples of pharmaceuticals. The sensor presented good sensitivity, rapid detection of CAR, and quick and easy preparation. Furthermore, the material used as modifier has a simple synthesis and its amount utilized is very small, thus illustrating the economic feasibility of this sensor.
\end{abstract}

Keywords: molecularly imprinted polymer; multi-walled carbon nanotubes; glassy carbon electrode; carvedilol; tablet sample

\section{Introduction}

The development of analytical methods that are increasingly selective and sensitive is of paramount importance for different areas, including food, environmental, pharmaceutical, and other sectors. At this point, the analytical sciences play a key role, and among analytical techniques, electrochemical techniques are noteworthy [1]. This statement is justified due to some of its advantageous features, such as high sensitivity and selectivity, moderate cost, portability, rapid responses, possibility of system miniaturization, and analysis of complex matrices [2,3]. Nevertheless, the utilization of electrodes in their original form without adding any other component limits its use for sensitivity, stability, and many other reasons. Thus, aiming to improve the features of electrochemical sensors, chemically modified electrodes (CMEs) have arisen for this purpose $[4,5]$. The term "chemically modified electrodes" was initially used by Murray and collaborators in the 1970s [6]. 
CMEs are electrodes with chemically active species, resulting from the immobilization of a modifying agent on the surface of a base electrode. The purpose of this modification is to preset and control the physical-chemical nature of the electrode-solution interface as a means of altering the reactivity and selectivity of the base sensor [7]. The modification of these electrodes can be done in several ways and using different materials. A new alternative in the practice of modifying electrodes that deserves highlighting is the use of molecularly imprinted polymers (MIPs) [8,9]. MIPs have been attracting considerable attention since the last decade; when they appeared as a promising tool for the development of systems with biomimetic recognition, similar to substrate-enzyme and/or antigen-antibody specific systems. Advantages of MIPs regarding biological materials include easy preparation, low cost, and simple storage (which is usually room temperature and for extended periods), among others [10]. The use of MIPs stands out for its acquired selectivity. This selectivity is due to molecular recognition of the imprinted polymer, which is obtained from the analyte molecule of interest $[10,11]$.

Conventionally, MIPs are synthesized by the bulk method, where the reaction is carried out in a homogeneous system. There are several steps for the synthesis of MIPs, such as carefully establishing the choice of the employed monomer and the analyte of interest, which must interact strongly to form a stable complex. This analyte-monomer interaction can occur through covalent bonds, which have more selective sites, but this would restrict the applicability of the MIPs to just a few analytes. The interaction can also occur by non-covalent bonds, which have fewer selective sites, but is more commonly used because of the greater flexibility of application to MIPs for different analytes [11,12].

Another important parameter that influences stability of the formation of "analyte-monomer" complex is the solvent. The substance chosen as solvent must provide a soluble medium without interfering in the interaction between analyte-monomer. The solvent should also induce the formation of pores that will facilitate the diffusion of analyte through the selective sites. Such solvents are called porogenic [10]. Finally, selectivity of these polymers is also ensured by the use of reagents that promote crosslinking in the polymer, thus allowing thermal and mechanical stability of the "analyte-monomer" complex. Also necessary is the addition of a radical initiator to the reactional medium in order to initiate the polymerization reaction $[1,10]$.

MIPs have proved to be an excellent tool for analytical chemistry due to their versatility of applications, including their use in pre concentration methods, such as solid-phase extraction (SPE) [13] and solid-phase microextraction (SPME) [14]; in separation processes, such as high-performance liquid chromatography (HPLC) [15], capillary electrophoresis (CE) [16], capillary electrochromatography (CEO) [17], and thin layer chromatography (TLC) [18]; and a growing interest in the use of these polymers in electroanalytical methods. Among them, the utilization of sensors stands out due to some unique features, such as low cost, portability, and the possibility of miniaturization, thus allowing the obtainment of information in situ and in real time [3,6].Even with such features, sensors can suffer from lack of selectivity. The use of MIP stands out for the obtainment of highly selective sensors [1].

Benilda et al. [19] reported the use of MIP in a sensor for determination of the antibiotic chloramphenicol. The sensor exhibited low cost and showed to be promising for the quantification of chloramphenicol residues in food products. Gu et al. [20] used MIP with an enzyme to enhance the catalytic efficiency of the sensor for determination of metronidazole. This sensor showed a low limit of detection and a good response for metronidazole determination. Another study using MIP was conducted by Reza and Motaharian [21], in which they developed a sensor based on a carbon-paste electrode modified with MIP for determination of diazepam in tablets and in human serum samples. The sensor showed a good response for diazepam. Abdelrehim et al. [22] utilized MIP as a modifier for a carbon-paste electrode to identify famciclovir (FCV). This study presented a low limit of detection and a good application for FCV determination in pharmaceutical preparations.

In this way, the use of imprinting technology is an excellent alternative for obtaining new voltammetric methods, especially when associated with materials that facilitate electron exchange with the electrode surface, as in the case of carbon nanotubes (CNTs). 
Iijima synthesized carbon nanotubes for the first time in 1991, and since then, CNTs have aroused great interest for different applications. They have distinct features, such as electronic properties, high mechanical strength, and their chemical properties-in particular, their thermal conductivity and electrical conductivity attracted attention for their excellence [23,24].

CNTs are formed by carbon hexagonal arrangements disposed in graphene sheets that are rolled into a cylindrical shape with diameters in the nanometer scale. From a structural point of view, there are two types of CNTs. Single-walled carbon nanotubes (SWNTs), which can be viewed as a single graphene sheet rolled on itself to form a cylindrical tube, and multiwalled carbon nanotubes (MWCNTs), comprising a set of three or more concentric nanotubes rolled up on each other [23].

The modified electrodes are an outstanding alternative for determining substances of pharmaceutical and medical interest, and others, due to features such as selectivity, sensibility, low cost, and portability.

A substance whose determination presents is of significance, in both pharmaceuticals and human plasma, is carvedilol (CAR). CAR belongs to the third generation of $\beta$-blockers, which includes, besides the $\beta$-blocking function, a vasodilator function due to the $\alpha$-adrenoceptor. CAR is used in the treatment of severe congestive heart failure and hypertension [25]. The CAR structure is shown in Figure 1.

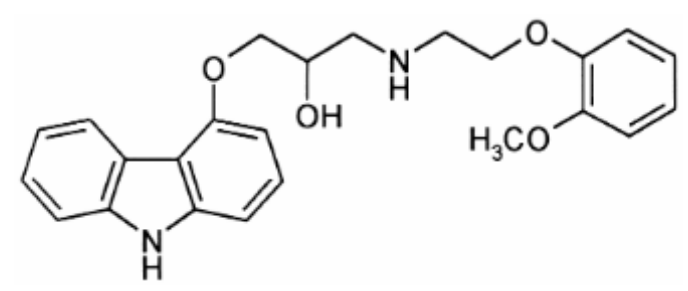

Figure 1. Molecular structure of carvedilol.

Beta-adrenergic blockers are a class of drugs that possess the ability to block $\beta$ noradrenaline receptors. Beta-adrenergic receptors are divided into two subtypes, $\beta 1$ and $\beta 2$, which are present in different concentrations in body tissues [25,26].

Beta-adrenergic blockers may also be divided into three generations in accordance with the degree of cardio selectivity compared to the blocking effect of $\beta 1$ and $\beta 2$ receptors. CAR is in the third generation, presenting nonspecific vasodilator properties [26,27].

CAR has $\alpha 1$ vessel-dilating action; moreover, it has a high antioxidant effect and is an oxygen radical scavenger, thus protecting heart membranes from lipid peroxidation induced by these radicals [27]. As cardiovascular diseases are a major group of diseases, considering the frequency at which they occur and the number of deaths related to them, the quantitative determination of CAR in pharmaceuticals and in human plasma is important, mainly for quality control, as more and more people need medication to control these cardiovascular diseases [2,27].

In this context, many analytical techniques have been employed for determination of CAR, such as high-performance liquid chromatography [28], spectrophotometry [29], capillary electrophoresis [30], and electrochemistry [2]. Electrochemical techniques stand out because (1) they allow investigating the redox properties of the studied drug; (2) have rapid, sensitive, and selective responses; (3) render system miniaturization possible; and (4) permit analysis of complex matrices [2]. However, it must be pointed out that the use of MIP integrated on electrochemical devices for larger molecules, such as the carvedilol, is not so straightforward, because such molecules can hinder the creation of selective binding sites in the MIP. Therefore, the highlight of the proposed method relies upon the synthesis of MIP for carvedilol, which has been little exploited due to the molecule's larger size, and its integration onto the surface of transducer electrode in the presence of multiwalled carbon nanotube. The feasibility of the sensor was verified using electroanalytical analysis of CAR in pharmaceutical formulations. 


\section{Experimental}

\subsection{Reagents and Solutions}

Multiwalled carbon nanotubes (MWCNTs)-99\% purity, diameter between 6 and $13 \mathrm{~nm}$, and length between 2.5 and $20 \mu \mathrm{m}$-were acquired from Nanocyl ${ }^{\circledR}$ (Auvelais, Belgium), carvedilol (CAR) was supplied by Sigma-Aldrich ${ }^{\circledR}$ (St. Louis, MO, USA), dimethylformamide (DMF) was purchased from F.MAIA Industry and Trade Ltda. ${ }^{\circledR}$ (Cotia, Brazil), phosphoric acid was purchased from Qhemis ${ }^{\circledR}$ (Indaiatuba, Brazil), boric acid was acquired from Labsynth ${ }^{\circledR}$ (Diadema, Brazil), acetic acid was purchased from Labsynth ${ }^{\circledR}$ (Diadema, Brazil), methanol was acquired from J.T.Baker ${ }^{\circledR}$ (Ecatepec Estado de Mexico)Nafion was supplied by Sigma-Aldrich ${ }^{\circledR}$ (St. Louis, MO, USA), potassium chloride was purchased from Sigma-Aldrich ${ }^{\circledR}$ (St. Louis, MO, USA), hydrochloric acid was acquired from Vetec Química Fina ${ }^{\circledR}$ (Industrial District of Duque de Caxias, Brazil ), and sodium hydroxide was supplied by Sigma-Aldrich ${ }^{\circledR}$ (St. Louis, MO, USA). For the synthesis of MIP, the following reagents and solvents were used:methacrylic acid (Sigma-Aldrich; Japan), chloroform (Tedia ${ }^{\circledR}$; Fairfield, CA, USA), (J. T. Baker ${ }^{\circledR}$; Ecatepec Estado de Mexico, México), methanol (J.T. Baker; Ecatepec Estado de Mexico), ethylene glycol dimethacrylate (Sigma-Aldrich; USA) and 4,4'-azobis-(4-cyanopentanoic acid) (Santa Cruz Biotechnology). All chemical reagents were analytical grade and solutions were prepared in distilled and deionized water (resistivity $>18 \mathrm{M} \Omega \cdot \mathrm{cm}^{-1}, 25{ }^{\circ} \mathrm{C}$; purification system Milli-Q ${ }^{\circledR}$ Millipore, Bedford, MA, USA).

\subsection{Instrumentation}

Electrochemical measurements were performed with a Multi Autolab potentiostat/galvanostat, model PGSTAT101 Ecochemie, controlled by Nova 1.11 software. The system used for obtaining electrochemical measurements consisted of a glass cell containing five orifices: three for the electrodes, one for gas inlet $\left(\mathrm{N}_{2}\right)$, and one for addition of reagents. Auxiliary and reference electrodes were made of a platinum wire spiral and $\mathrm{Ag} / \mathrm{AgCl}$, respectively. A glassy carbon disk electrode with a diameter of $3 \mathrm{~mm}$ was used as a bare electrode. Analysis by Fourier-transform infrared spectroscopy (FT-IR) was carried out using a Fourier Transform Spectrometer (Bomem Hartmann \& Braun, MB series, Quebec, Canada), operating between 4000 and $400 \mathrm{~cm}^{-1}$ at $4 \mathrm{~cm}^{-1}$ resolution, using the conventional method (KBr pellet). Thermo gravimetric analysis (TGA) was conducted in a thermo balance (2950 Thermal Analysis Instrument, Instrument, New Castle, DE, USA) with a heating rate of $10{ }^{\circ} \mathrm{C} \cdot \mathrm{min}^{-1}$, under nitrogen flow $\left(50 \mathrm{~mL} \cdot \mathrm{min}^{-1}\right)$ from 25 to $600{ }^{\circ} \mathrm{C}$. The scanning electron microscopy (SEM) images were obtained using a TM3000 Hitachi Analytical Table Top Microscope (Tarrytown, NY, USA) with an acceleration tension of $15 \mathrm{kV}$.

\subsection{Synthesis of MIP}

Molecularly imprinted polymer was synthesized by using $1.0 \mathrm{mmol}$ of CAR, $4.0 \mathrm{mmol}$ of methacrylic acid dissolved in $10.0 \mathrm{~mL}$ of chloroform, $1.0 \mathrm{~mL}$ of acetonitrile, and $1.0 \mathrm{~mL}$ of methanol (J.T. Baker; Mexico). Next, $20.00 \mathrm{mmol}$ of ethylene glycol dimethacrylate and $0.3 \mathrm{mmol}$ of $4,4^{\prime}$-azobis-(4-cyanopentanoic acid) were added to the mixture. The solution was sonicated in an ultrasonic bath (Ultra Clener-Unique, Brazil) for $10 \mathrm{~min}$, followed by nitrogen flow for $5 \mathrm{~min}$. Taking into account that polymer synthesis was carried out through radical polymerization, the removal of dissolved oxygen was needed, and was accomplished using nitrogen flow. The solution was sealed in vials, and then placed in an oven at $80^{\circ} \mathrm{C}$ for $24 \mathrm{~h}$. Following successful polymerization, the material was washed with methanol/acetic acid $(9: 1, v / v)$ several times using an ultrasonic bath. The removal of template from cavities of polymer has been shown to be efficient when using a methanol/acetic mixture [31]. Total removal of CAR from MIP was monitored by HPLC. In order to remove the residual acid molecules that would potentially affect the rebinding process, upon removal of template, successive washings of polymer with deionized water were carried out until $\mathrm{pH} \cong 7.0$. The blank polymer (NIP, non imprinted polymer) was synthesized similar to MIP, but without template. 


\subsection{Preparation of Suspension for Electrode Modification}

The suspension used for glassy carbon electrode modification was prepared from $10 \mathrm{mg}$ of MIP, $10 \mathrm{mg}$ of MWCNT, and $1.0 \mathrm{~mL}$ of DMF. This suspension was placed in an ultrasonic bath for $5 \mathrm{~min}$, and $10.0 \mu \mathrm{L}$ of sonicated suspension was then dripped onto the surface of a glassy carbon electrode (GCE) and kept at rest at room temperature to volatilize the solvent. The same procedure was carried out for the blank polymer (NIP).

\subsection{Optimization of Experimental Parameters}

Firstly, to evaluate the influence of electrode modification on the determination of CAR, cyclic voltammograms (CVs) were recorded in the potential window varying from -0.7 to $0.5 \mathrm{~V}$ using the unmodified glassy carbon electrode (GCE), GCE modified with MWCNT, and GCE modified with MIP and MWCNT. After that, cyclic voltammograms were performed, varying the concentration of MIP in suspension $(50 \%, 60 \%, 65 \%$, and $70 \%(\mathrm{~m} / \mathrm{m})$ with respect to MWCNT). Then, the influence of Nafion was evaluated in order to obtain a better fixation of the suspension on the surface of GCE. The influence of $\mathrm{pH}$ (7.0-9.0) on the analytical response of the modified sensor was investigated by using $0.1 \mathrm{~mol} \cdot \mathrm{L}^{-1}$ Britton-Robinson (BR) buffer. Subsequently, the effect of BR concentration was studied in the range from 0.05 to $0.30 \mathrm{~mol} \cdot \mathrm{L}^{-1}$, while the influence of $\mathrm{KCl}$ concentration was evaluated from 0.10 to $1.00 \mathrm{~mol} \cdot \mathrm{L}^{-1}$.

\section{Results}

\subsection{Characterization of MIP and NIP}

FT-IR was carried out to evaluate the presence of functional groups in the polymers. In Figure 2, one can observe the presence of a similar chemical composition for MIP and NIP. This observation is explained taking into account that both materials were synthesized using the same reagents, except for the addition of template to MIP. The band at $1649 \mathrm{~cm}^{-1}$ was attributed to $\mathrm{sp}^{2}$ hybridized carbon stretching, which was believed to be from unsaturated reagents that have not been consumed or by $\mathrm{OH}$ deformation from adsorbed water. The band at $1729 \mathrm{~cm}^{-1}$ is characteristic of carboxyl stretch from methacrylic acid, and the band at $3563 \mathrm{~cm}^{-1}$ is ascribed to hydroxyl stretch. The band at $1264 \mathrm{~cm}^{-1} \mathrm{can}^{-1}$ be assigned to stretching of $\mathrm{COOH}$ from methacrylic acid, while the band at $1160 \mathrm{~cm}^{-1}$ is attributed to $\mathrm{O}-\mathrm{C}(\mathrm{O})-\mathrm{C}$ from segments of ethylene glycol dimethylacrylate (EGDMA) [32].

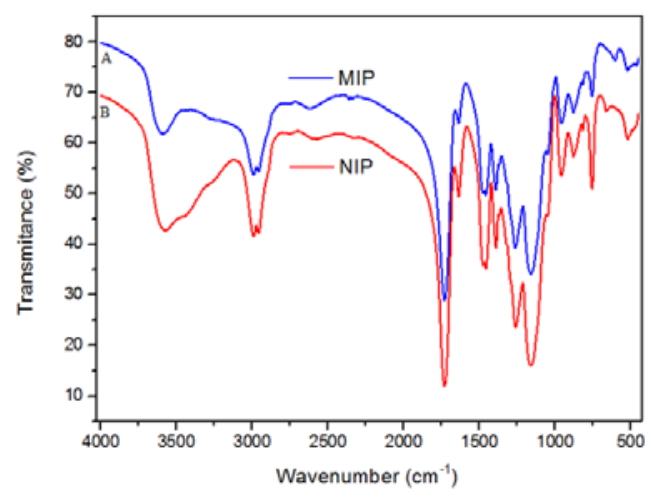

Figure 2. Fourier-transform infrared (FT-IR) spectra of molecularly imprinted polymer (MIP) and no imprinted polymer (NIP).

Thermo gravimetric analysis (TGA) evaluated the thermal stability of the materials. As may be observed in Figure 3, TG curves for MIP and NIP have the same event of mass loss. The first region was around $100{ }^{\circ} \mathrm{C}$, which might be related to the evaporation of water and/or solvent (chloroform) not consumed during the synthesis. A large weight loss was observed from 300 to $450{ }^{\circ} \mathrm{C}$, which is 
attributed to decomposition of the methacrylic acid segment of the polymeric matrix as well as the decomposition of EGDMA [33].Therefore, the achieved results demonstrated that the polymer is thermally stable at operating temperature.
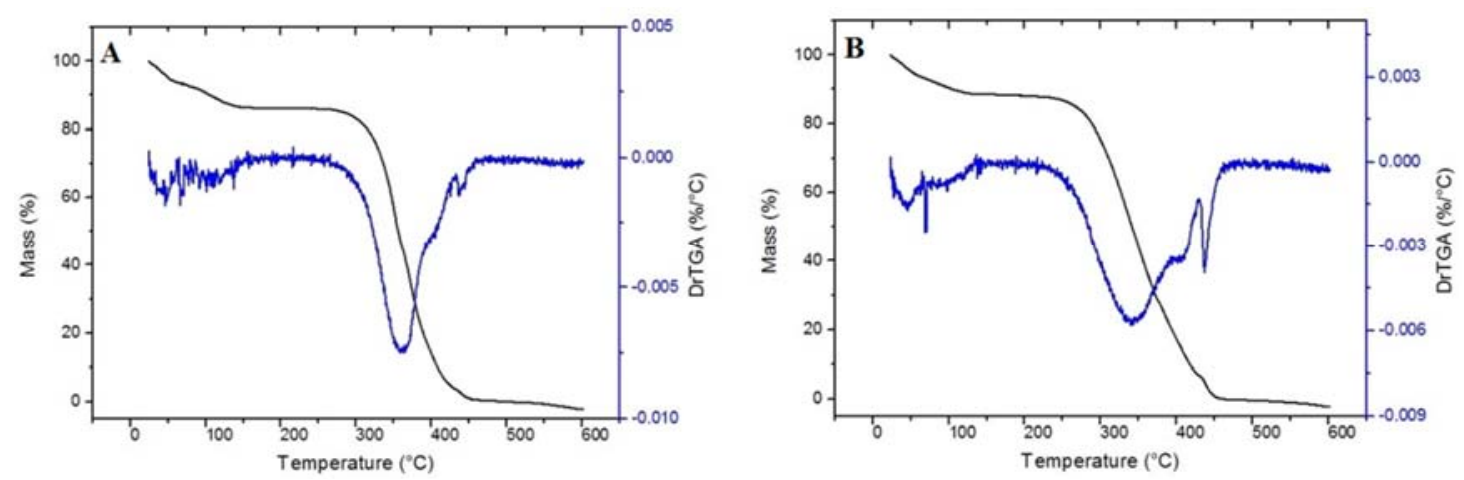

Figure 3. Thermo gravimetric analysis (TGA) and TGA derivative curves of (A) MIP and (B) NIP.

SEM images provided an analysis of morphological structure of MIP and NIP. As shown in Figure 4, micrographs of MIP and NIP did not show any significant differences from one another, thus demonstrating that template did not influence the morphological features of MIP. Such a result indicates that the improved performance of MIP compared to NIP is attributed to imprinted sites and not morphological features. Analyzing Figure 4, one can note the materials have irregular surface, composed of particles with non uniform sizes, which may result in the material adsorptive capacity. This morphological profile is very common for polymers synthesized by the bulk method.
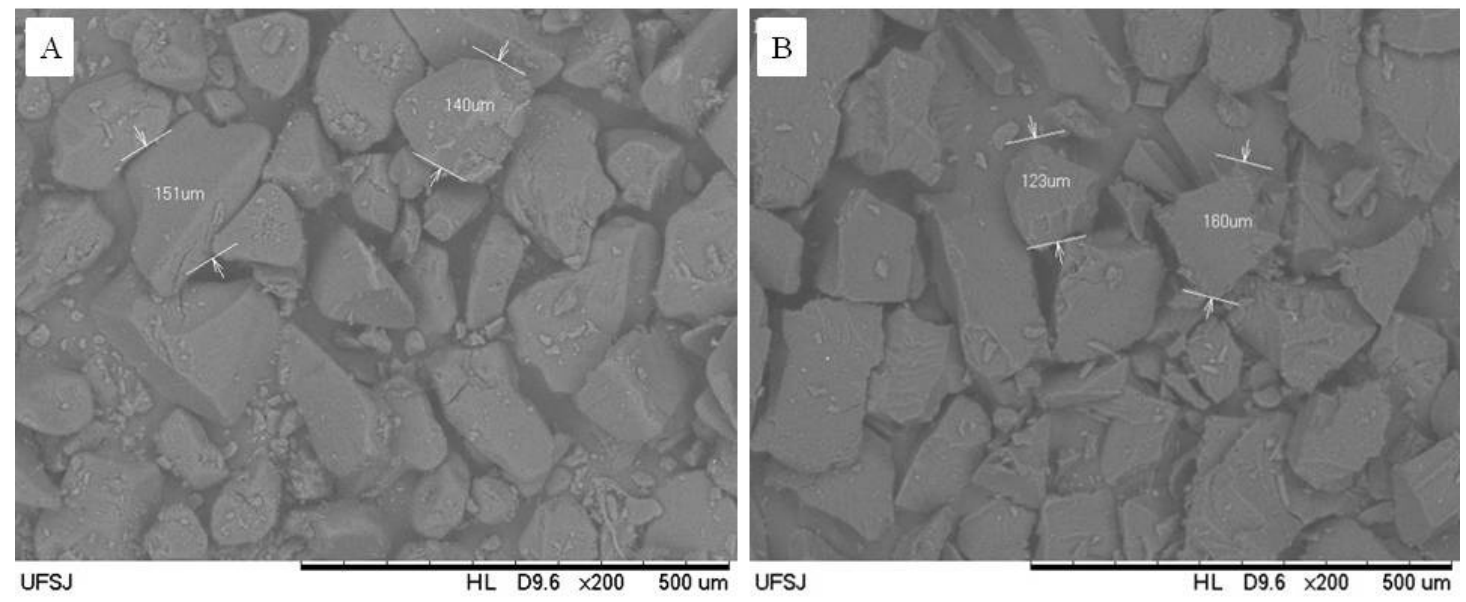

Figure 4. Scanning electron microscopy (SEM) micrographs of MIP (A) and NIP (B) at $200 \times$ magnification.

\subsection{Electrochemical Behavior of GCE-MIP-MWCNT and GCE-NIP-MWCNT towards the Reduction of Carvedilol}

Figure 5 shows the cyclic voltammogram of CAR recorded with GCE, GCE modified with MWCNT, and GCE modified with MIP and MWCNT. As observed, there is an increase of cathodic peak current for carvedilol when using the bare electrode modified with MIP and MWCNT. This result is attributed to the synergic effect of MWCNT, which assists in the transfer of electrons, and the MIP, making the working electrode more selective for CAR. Moreover, the presence of two redox pairs can be observed, which was reported by other authors such as Dogan and Ozkan [34] and Rofouei et al. [35]. On the other hand, it is well known that the electrooxidation of CAR is irreversible, thus the presence 
of MIP and MWCNT may improve the reversibility of the CAR redox process. However, this behavior requires further study.

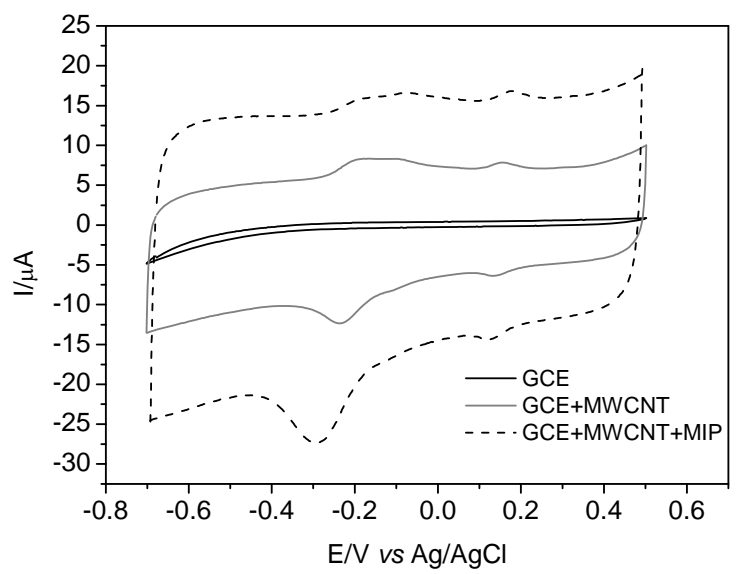

Figure 5. Evaluation of the influence of MIP in the presence of $250 \mu \mathrm{mol} \cdot \mathrm{L}^{-1}$ of carvedilol (CAR).

In order to evaluate the selectivity of the MIP, records of cyclic voltammograms were carried in absence and presence of CAR using the modified electrode with NIP (non imprinted polymer). As can be seen from Figure 6, no response to CAR was observed, thus indicating the MIP plays an important role on the electrochemical recognition of CAR.

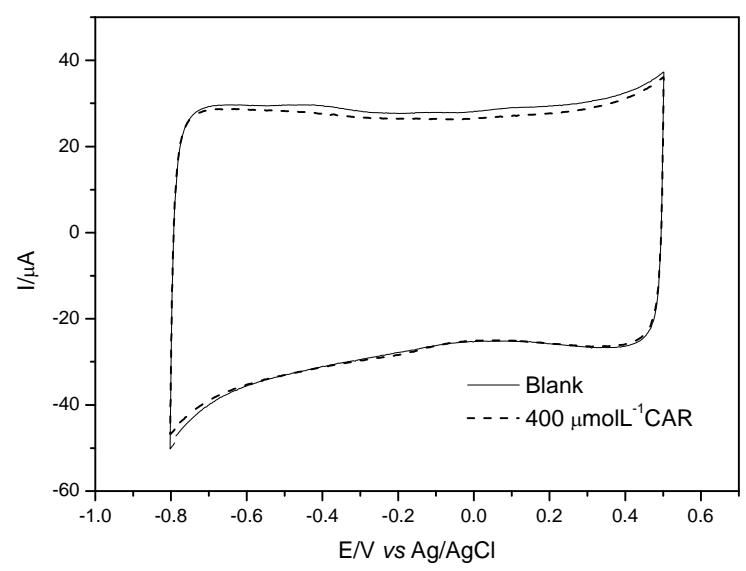

Figure 6. Voltammograms obtained for $400 \mu \mathrm{mol} \cdot \mathrm{L}^{-1}$ CAR determination, employing glassy carbon electrode (GCE)-NIP-MWCNT (multiwalled carbon nanotubes) under optimized experimental conditions: $0.25 \mathrm{~mol} \cdot \mathrm{L}^{-1}$ of Britton-Robinson buffer $\mathrm{pH} 8.5$ and $0.10 \mathrm{~mol} \cdot \mathrm{L}^{-1} \mathrm{KCl}$ solution.

Considering the superior electrochemical response to carvedilol when using the GCE modified with MIP and MWCNT, the influence of MIP proportion $(50 \%-70 \%, \mathrm{~m} / \mathrm{m})$ in the suspension was evaluated. As observed from Figure 7, higher analytical signal was achieved by using $65 \%(\mathrm{~m} / \mathrm{m})$ of MIP in the suspension. When using $70 \%(\mathrm{~m} / \mathrm{m})$, the analytical signal was drastically decreased, most likely due to blocking of electron flow, since MIP is a nonconductive material. Also observed was a swelling effect and low physical stability of MIP from the surface of the glassy carbon electrode. Therefore, the proportion of $65 \%(\mathrm{~m} / \mathrm{m})$ MIP was used for further experiments. 


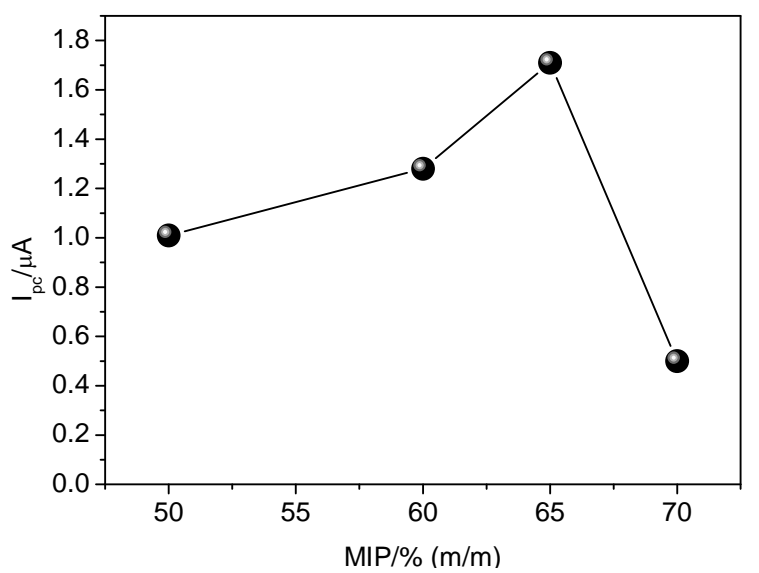

Figure 7. Variation of cathodic peak current $\left(\mathrm{I}_{\mathrm{pc}}\right)$ for the function of MIP percentage $(\mathrm{m} / \mathrm{m})$ in the suspension. Concentration of $250 \mu \mathrm{mol} \cdot \mathrm{L}^{-1}$ of CAR; $0.1 \mathrm{~mol} \cdot \mathrm{L}^{-1}$ Britton-Robinson buffer solution, $\mathrm{pH} 8.0$ at $\mathrm{v}=30 \mathrm{mV} \cdot \mathrm{s}^{-1}$.

The influence of Nafion ${ }^{\circledR} \%(\mathrm{~m} / \mathrm{v})$ on the performance of the sensor was also evaluated. Nafion ${ }^{\circledR}$ is a polymeric resin with excellent properties, such as chemical, mechanical, and thermal stability, selectivity for different cations, and high conductivity [36,37]. This polymer has been widely used for the fixation of particles onto electrode surface. However, due to its high mechanical strength, it can act as a barrier, thus hindering the diffusion of CAR towards the working electrode, resulting in decreased current variation. Table 1 shows the influence of volume of Nafion ${ }^{\circledR}$ deposited onto the modified electrode. As observed, the insertion of Nafion ${ }^{\circledR}$ onto the surface decreases the analytical signal. Therefore, the modification of glassy carbon electrode with MIP and MWCNT was carried out in the absence of Nafion ${ }^{\circledR}$.

Table 1. Evaluation of current variation for different proportions of Nafion $5 \%$ compared with an electrode without Nafion. Concentration of $250 \mu \mathrm{mol} \cdot \mathrm{L}^{-1}$ of CAR in $0.1 \mathrm{~mol} \cdot \mathrm{L}^{-1}$ Britton-Robinson buffer solution, $\mathrm{pH} 8.0$.

\begin{tabular}{cc}
\hline Electrode Configuration & $\Delta \mathbf{I} / \mu \mathbf{A}$ \\
\hline GCE + MWCNT + MIP & 1.71 \\
GCE + MWCNT + MIP +Nafion $(10 \mu \mathrm{L})$ & 0.71 \\
GCE + MWCNT + MIP + Nafion $(5 \mu \mathrm{L})$ & 0.95 \\
\hline
\end{tabular}

\subsection{Influence of $\mathrm{pH}$ on the Performance of the Sensor}

The influence of $\mathrm{pH}$ on the analytical signal of CAR was evaluated in the range of 7.0-9.0, using $0.1 \mathrm{~mol} \cdot \mathrm{L}^{-1}$ Britton-Robinson buffer. As seen in Figure 8 , the analytical signals were obtained were better in the alkaline range (8.5-9.0), thus $\mathrm{pH} 8.5$ was adopted for further experiments. This result can be explained by the proximity of $\mathrm{pH}$ in relation to CAR $\mathrm{pKa}$, which is 7.831. At $\mathrm{pH} 8.5$, there exist two forms of CAR in aqueous medium, $36.4 \%$ in its molecular form and $63.6 \%$ in its protonated form, while at $\mathrm{pH} 9.0,64.4 \%$ is in its molecular form and $35.5 \%$ in its protonated form. At very low $\mathrm{pH}$ values, formation of deprotonated species of CAR is favored. From these results, it is possible to infer that interaction of CAR with binding sites of MIP may take place by both hydrogen bonding and electrostatic attraction. Moreover, as reported in literature [34,35], alkaline $\mathrm{pH}$ values between 8.0 and 11.0 promote greater deprotonation in species and, consequently, higher current variation $(\Delta \mathrm{I})$. 


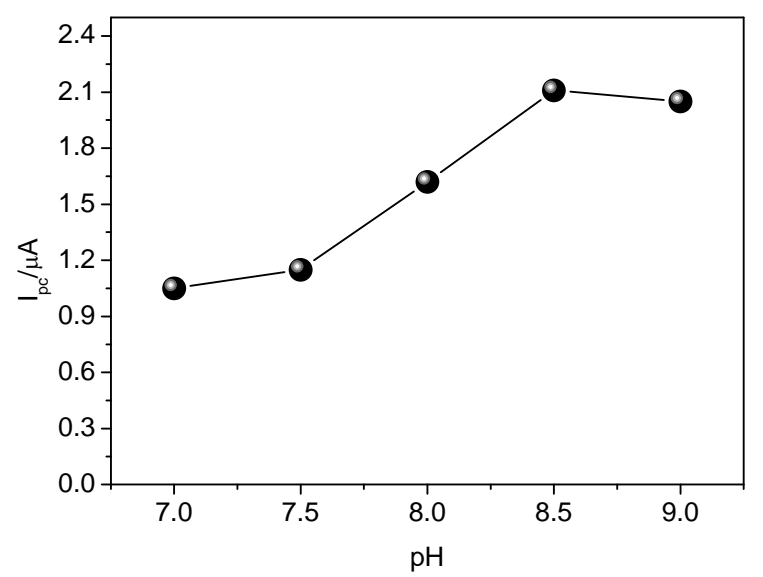

Figure 8. Influence of $\mathrm{pH}$ on the current variation $(\Delta \mathrm{I})$ in $250 \mu \mathrm{mol} \cdot \mathrm{L}^{-1}$ of $\mathrm{CAR}$. Measurements were carried out in $0.1 \mathrm{~mol} \cdot \mathrm{L}^{-1}$ Britton-Robinson buffer solution.

\subsection{Concentration of Britton-Robinson Buffer Solution}

In order to assess the best sensor response regarding different concentrations of Britton-Robinson solution, a study was conducted at different concentrations $\left(0.05,0.01,0.15,0.20,0.25\right.$, and $\left.0.30 \mathrm{~mol} \cdot \mathrm{L}^{-1}\right)$. The greater variation in current occurred at electrolyte concentration of $0.25 \mathrm{~mol} \cdot \mathrm{L}^{-1}$. Figure 9 shows an increase of current variation up to $0.25 \mathrm{~mol} \cdot \mathrm{L}^{-1}$, then a decrease. This is probably due to the gradual increase of charge carriers up to $0.25 \mathrm{~mol} \cdot \mathrm{L}^{-1}$, and above this value, the charge carriers may block sites of MIP, thus decreasing current variation. This result can be rationalized by bearing in mind that interaction of CAR with binding sites of MIP may also take place by electrostatic attraction, as reported in the aforementioned studies regarding the influence of $\mathrm{pH}$. Therefore, it seems that using higher buffer concentration decreases the interaction between CAR and the binding sites of MIP.

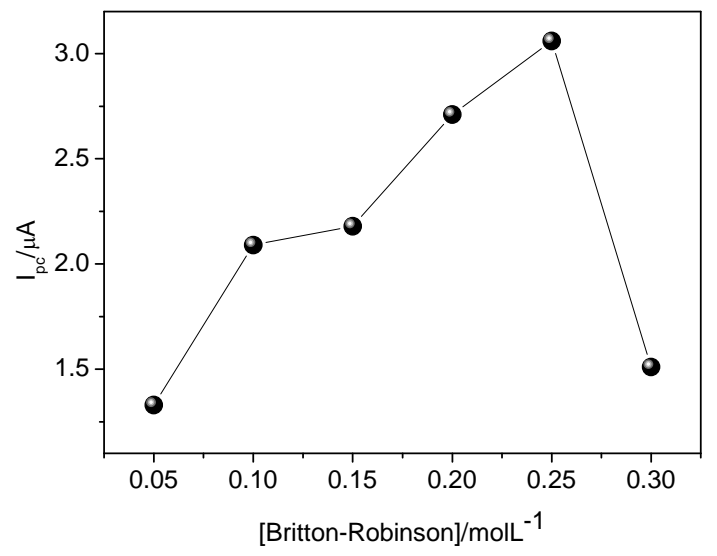

Figure 9. Influence of concentration of Britton-Robinson buffer solution at $\mathrm{pH} 8.5$ on the current variation $(\Delta \mathrm{I})$. Solution of $250 \mu \mathrm{mol} \cdot \mathrm{L}^{-1}$ of CAR.

\subsection{Influence of $\mathrm{KCl}$ Solution}

Different concentrations of $\mathrm{KCl}$ solution $\left(0.1,0.2,0.3,0.5,1.0 \mathrm{~mol} \cdot \mathrm{L}^{-1}\right)$ were evaluated, aiming to increase the mass transport of the bulk solution to the working electrode surface. The best analytical response was observed for $0.1 \mathrm{~mol} \cdot \mathrm{L}^{-1} \mathrm{KCl}$, at which a larger current variation $(\Delta \mathrm{I})$ was achieved. At higher concentrations of $\mathrm{KCl}$, a decrease in current variation $(\Delta \mathrm{I})$ is observed. This probably occurs because in the presence of a large concentration of ions, the access to the MIP cavity by analyte of interest can be hindered, leading to a reduction of current variation $(\Delta \mathrm{I})$. 


\subsection{Influence of Scan Rate}

The influence of scan rate on the reduction of CAR was evaluated from 5.0 to $500 \mathrm{mV} \cdot \mathrm{s}^{-1}$ (Figure 10). Data used for construction of graphs were obtained from CV analysis in $0.25 \mathrm{~mol} \cdot \mathrm{L}^{-1}$ Britton-Robinson buffer solution $(\mathrm{pH} 8.5)$ and $0.1 \mathrm{~mol} \cdot \mathrm{L}^{-1} \mathrm{KCl}$ solution. The linear relationship obtained suggests the reduction process is controlled by adsorption.

To confirm that the process is controlled by adsorption, the relation between log peak current and $\log$ scan rate was evaluated, as shown in Figure 10b. Based on this, the process was characterized as being controlled by adsorption, since the value obtained for the slope, 0.7924 , tends to the theoretical value of 1 , which expresses an ideal reaction controlled by adsorption, as has been documented by literature [34,38].
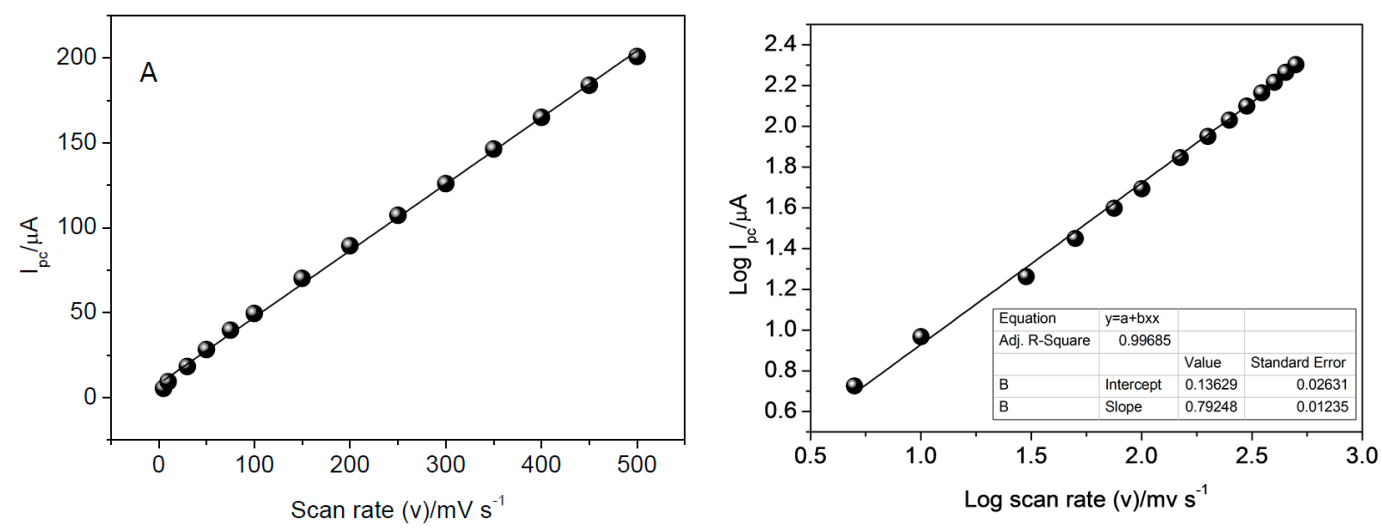

Figure 10. (A) Relation between cathodic peak current $\left(\mathrm{I}_{\mathrm{pc}}\right)$ versus scan rate $(\mathrm{v})$ in intervals of 5 to a maximum of $500 \mathrm{mV} \cdot \mathrm{s}^{-1}$. Concentration of $250 \mu \mathrm{mol} \cdot \mathrm{L}^{-1}$ of $\mathrm{CAR}, 0.25 \mathrm{~mol} \cdot \mathrm{L}^{-1}$ Britton-Robinson buffer solution at $\mathrm{pH} 8.5$ and $0.1 \mathrm{~mol} \cdot \mathrm{L}^{-1} \mathrm{KCl}$ solution; (B) Relation between log cathodic peak current $\left(\mathrm{I}_{\mathrm{pc}}\right)$ versus $\log$ scan rate $(\mathrm{v})$, using the same conditions of Figure 10a.

\subsection{Final Analytical Conditions}

After optimization of experimental parameters, it was possible to build the analytical curve with subsequent additions of $0.05 \mathrm{~mol} \cdot \mathrm{L}^{-1}$ of CAR. Voltammograms obtained with subsequent additions of CAR in the electrochemical cell containing $0.25 \mathrm{~mol} \cdot \mathrm{L}^{-1}$ Britton-Robinson buffer at pH 8.5 and $0.1 \mathrm{~mol} \cdot \mathrm{L}^{-1} \mathrm{KCl}$ solution are depicted in Figure 11A. As can be observed in Figure 11b, analyte additions have a good linearity between 50 and $325 \mu \mathrm{mol} \cdot \mathrm{L}^{-1}$ of CAR, showing a decline after fifth addition, demonstrating that the reduction process of CAR occurs through adsorption. This behavior is confirmed by what was observed in the previous study. The calibration curve obtained for determination of CAR showed a sensitivity of $0.008 \mu \mathrm{A} \cdot \mathrm{L} \cdot \mu \mathrm{mol}{ }^{-1}$.

Limits of detection and quantification of the method were calculated employing the method based on the analytical curve parameters (ICH, 1995) [39]. In this method, the limit of detection (LD) can be expressed by Equation (1) and the limit of quantification (LQ) by Equation (2):

$$
\begin{aligned}
& \mathrm{LD}=3 \times \mathrm{s} / \mathrm{a}, \\
& \mathrm{LQ}=10 \times \mathrm{s} / \mathrm{a},
\end{aligned}
$$

where $s$ is the estimated standard deviation of background and a is the slope of the curve. The value of s was found to be $0.0432 \mu \mathrm{A}$, thus allowing us to obtain LD and LQ equal to $16.14 \mathrm{mmol} \cdot \mathrm{L}^{-1}$ and $53.8 \mathrm{mmol} \cdot \mathrm{L}^{-1}$, respectively. 

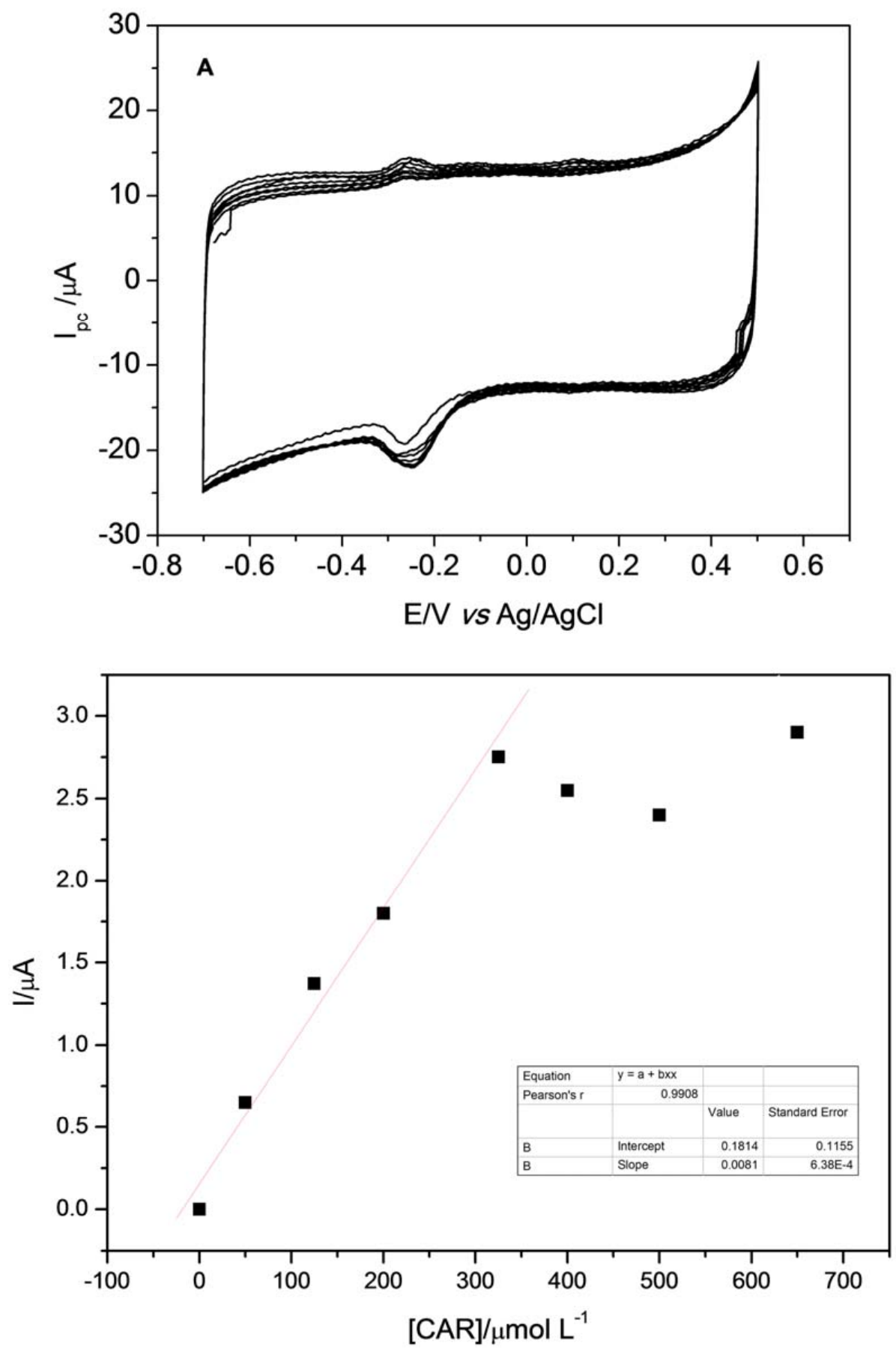

Figure 11. (A) Voltammograms for determination of CAR obtained for additions of 50-625 $\mu \mathrm{mol} \cdot \mathrm{L}^{-1}$; (B) Analytical curve constructed from voltammograms (Figure 11A). Measurements performed by using 65\% MIP/MWCNT under optimized experimental conditions, in $0.25 \mathrm{~mol} \cdot \mathrm{L}^{-1}$ Britton-Robinson buffer solution at $\mathrm{pH} 8.5$ and $0.1 \mathrm{~mol} \cdot \mathrm{L}^{-1} \mathrm{KCl}$ solution.

The proposed sensor showed a linear response in the concentration range from $50-325 \mathrm{mmol} \cdot \mathrm{L}^{-1}$, with a linear coefficient of $0.9755(\mathrm{n}=8)$. The precision of the present method, as assessed for repeatability $(\mathrm{n}=10)$, was very satisfactory at $3.8 \%$ (relative standard deviation, RSD) for the concentration of $250 \mu \mathrm{mol} \cdot \mathrm{L}^{-1}$ of CAR. Moreover, the repeatability of sensor preparation was evaluated on 10 different days and cyclic voltammograms were recorded under optimum condition using $250 \mu \mathrm{mol} \cdot \mathrm{L}^{-1}$ of CAR. The RSD value regarding the cathodic peak current of CAR is $4.7 \%$, 
which clearly demonstrates a well-controlled experimental method, with good repeatability for the sensor preparation.

In order to assess the performance of the proposed sensor, works regarding the determination of carvedilol through sensors were sought in the literature. Dogan and Ozkan [34] conducted a study where they determined carvedilol by using a glassy carbon electrode. The electrode exhibited linear response for carvedilol in the concentration range of $0.2-20 \mu \mathrm{mol} \cdot \mathrm{L}^{-1}$ and showed a limit of detection of $0.0021 \mu \mathrm{mol} \cdot \mathrm{L}^{-1}$.

Rofouei et al. [35] performed another study for carvedilol determination. In this work, they built an electrode modified with ordered mesoporous carbon for determination of carvedilol in medicines and biological fluids. The sensor presented a working range for carvedilol concentrations from 0.1 to $23 \mathrm{mmol} \cdot \mathrm{L}^{-1}$. Limit of detection was found to be $0.034 \mu \mathrm{mol} \cdot \mathrm{L}^{-1}$ in Britton-Robinson solution, $\mathrm{pH} 8$.

Lastly, Soleymanpour and Ghasemian [40] performed a study for determination of carvedilol. They determined carvedilol using a carbon-paste electrode based on the incorporation of a carvedilol-phosphotungstate complex. This sensor showed a linear response for CAR in concentration range of $0.3-1000 \mu \mathrm{mol} \cdot \mathrm{L}^{-1}$ and a limit of detection of $0.15 \mu \mathrm{mol} \cdot \mathrm{L}^{-1}$.

As observed, the previously developed methods have presented lower limits than the one herein obtained. Despite this finding, one should note that high detectability for pharmaceutical analysis is not imperative; on the contrary, the use of simple, quick, and economic methods play a more important role. In addition, in our proposed method, cyclic voltammetry was used as an analytical technique, which is naturally less sensitive than amperometry and pulse voltammetric techniques.

\subsection{Evaluation of Interfering}

Selectivity is one of the most important characteristics of a sensor based on MIP. In order to evaluate the selectivity of the sensor towards other molecules, cyclic voltammograms for CAR at $400 \mu \mathrm{mol} \cdot \mathrm{L}^{-1}$ concentration in the presence of potentially interfering electroactive molecules at $4000 \mu \mathrm{mol} \cdot \mathrm{L}^{-1}$ concentration were recorded under optimum conditions. According to the results shown in Table 2, it can be observed that the sensor does not respond to the majority of molecules in the region employed for determination of CAR. Electrochemical responses were observed only for L-cysteine and L-ascorbic acid, which is attributed to the oxidation and/or reduction of these compounds in the carbon matrix of the sensor. Although some interferences have been observed, the application of the method in pharmaceutical samples can be successfully carried out, once L-cysteine and L-ascorbic acid are not found in tables of CAR.

Table 2. Relative response other electroactive molecules in comparison to carvedilol by using the proposed sensor (GCE-MIP-MWCNT).

\begin{tabular}{cc}
\hline Interferents & Relative Response (\%) \\
\hline L-ascorbic acid & 35.6 \\
Glycine & 0 \\
D-glucose & 0 \\
L-cysteine & 13.3 \\
Lactose & 0 \\
Leucine & 0 \\
Urea & 0 \\
\hline
\end{tabular}

The selectivity of the proposed method was also evaluated by the addition of excipients usually present in pharmaceutical formulations (sucrose, microcrystalline cellulose, povidove, croscarmellose sodium, silicon oxide, magnesion stearate, red ferric oxide, and talc). The carvedilol/excipient concentration ratio studied in the present study was $1: 10(\mathrm{~m} / \mathrm{m})$ and the analytical signals were compared with those in the absence of each excipient. From the achieved results, no interference was 
observed, thus allowing us to conclude that the proposed method proves will be successfully applied to pharmaceutical formulation.

\subsection{Application of Proposed Method}

The proposed sensor was applied for determination of CAR in pharmaceutical samples (Carvedilol, $3.125 \mathrm{mg}$, Biosintética ${ }^{\circledR}$ ) under optimized conditions. Table 3 illustrates a comparison between the value shown on the label and the result obtained using the proposed sensor. Good recovery of CAR can be observed. In order to check statistical differences between results, a Student $t$-test with a confidence level of $95 \%$ was applied to the $\mathrm{t}$-value was found to be 3.56 , which is lower than the critical value of 4.30 , demonstrating that there is no difference between the two values. The result demonstrates that the MIP-based sensor is an excellent alternative for carvedilol determination, featuring a rapid and inexpensive preparation.

Table 3. Determination of CAR in pharmaceutical product using the proposed method.

\begin{tabular}{cccc}
\hline Sample & Nominal Value $(\mathbf{m g})$ & Proposed Method $(\mathbf{m g})$ & Relative Error $\mathbf{( \% )}$ \\
\hline 1 & 3.125 & $3.409 \pm 0.138$ & 9.08 \\
\hline
\end{tabular}

\section{Conclusions}

This work demonstrated that the MIP-based sensor is a viable alternative for determination of CAR by cyclic voltammetry. The CAR reduction process is characterized as being controlled by adsorption, and it was found to be $\mathrm{pH}$-dependent. Optimization of experimental conditions provided a good linear response range and satisfactory detectability for the determination of CAR in a pharmaceutical sample. The method can be also considered to below in cost and easy to implement. For final remarks, the developed sensor shows the applicability of MIP for a sensing molecule with a large size, which has been a challenge in the field of chemical imprinting technology.

Acknowledgments: The authors would like to thank the Conselho Nacional de Desenvolvimento Científico e Tecnológico (CNPq) (Project No 481669/2013-2, 305552/2013-9, 472670/2012-3), Coordenação de Aperfeiçoamento de Pessoal de Nivel Superior (CAPES) (25/2014), FAPEMIG, Fundação Araucária do Paraná (163/2014), Laboratório de Espectroscopia da Central de Multiusuário da PROPPG, SANEPAR, SETI do Paraná, ESPEC-UEL and Instituto Nacional de Ciência e Tecnologia de Bioanalítica (INCT) (Project No. 573672/2008-3) for their financial support and fellowships. This study is also part of the project involving the RedeMineira de Química (RQ-MG) supported by FAPEMIG (Project: REDE-113/10; Project: CEX-RED-0010-14).

Author Contributions: Malena Karla Lombello Coelho: contributions regarding the development of analytical method Juliana de Fátima Giarola: contributions regarding the development of analytical method Anny Talita Maria da Silva: contributions regarding the synthesis of MIP César Ricardo Teixeira Tarley: contributions regarding the writing of the manuscript Keyller Bastos Borges: contributions regarding the synthesis of MIP Arnaldo César Pereira: contributions regarding the development of whole analytical method

Conflicts of Interest: The authors declare no conflict of interest.

\section{References}

1. Tarley, C.R.T.; Sotomayor, M.D.P.T.; Kubota, L.T. Polímeros biomiméticos em química analítica. Parte 2: aplicações de MP ("Molecularly Imprinted Polymers") no desenvolvimento de sensores químicos. Quim. Nova 2005, 28, 1087-1101. [CrossRef]

2. Shadjou, N.; Hasanzadeh, M.; Saghatforoush, L.; Mehdizadeh, R.; Jouyban, A. Electrochemical behavior of atenolol, carvedilol and propranolol on copper-oxide nanoparticles. Electrochim. Acta 2011, 58, 336-347. [CrossRef]

3. Lowinsohn, D.; Bertotti, M. Sensores eletroquímicos: considerações sobre mecanismos de funcionamento e aplicações no monitoramento de espécies químicas em ambientes microscópicos. Quim. Nova 2006, 29, 1318-1325. [CrossRef] 
4. Pereira, A.C.; Aguiar, M.R.; Kisner, A.; Macedo, D.V.; Kubota, L.T. Amperometric biosensor for lactate based on lactate dehydrogenase and Meldola Blue coimmobilized on multi-wall carbon-nanotube. Sens. Actuators $B$ Chem. 2007, 124, 269-276. [CrossRef]

5. Chu, H.; Wei, X.; Wu, M.; Yan, J.; Tu, Y. An electrochemiluminescent biosensor based on polypyrrole immobilized uricase for ultrasensitive uric acid detection. Sens. Actuators B Chem. 2012, 163, 247-252. [CrossRef]

6. Pereira, A.C.; Santos, A.D.; Kubota, L.T. Trends in amperometric electrodes modification for electroanalytical applications. Quim. Nova 2002, 25, 1012-1021.

7. Souza, M.F.B. Eletrodos quimicamente modificados aplicados à eletroanálise: Uma breve abordagem. Quim. Nova 1997, 20, 191-195. [CrossRef]

8. Zhang, X.; Peng, Y.; Bai, J.; Ning, B.; Sun, S.; Hong, X.; Liu, Y.; Liu, Y.; Gao, Z. A novel electrochemical sensor based on electropolymerized molecularly imprinted polymer and gold nanomaterials amplification for estradiol detection. Sens. Actuators B Chem. 2014, 200, 69-75. [CrossRef]

9. Qian, T.; Yu, C.; Zhou, X.; Ma, P.; Wu, S.; Xu, L.; Shen, J. Ultrasensitive dopamine sensor based on novel molecularly imprinted polypyrrole coated carbon nanotubes. Biosens. Bioelectron. 2014, 58, 237-241. [CrossRef] [PubMed]

10. Tarley, C.R.T.; Sotomayor, M.D.P.T.; Kubota, L.T. Polímeros biomiméticos em química analítica. Parte 1: preparo e aplicações de MIP (" Molecularly Imprinted Polymers") em técnicas de extração e separação. Quim. Nova 2005, 28, 1076-1086. [CrossRef]

11. Blanco-López, M.C.; Lobo-Castañón, M.J.; Miranda-Ordieres, A.J.; Tuñón-Blanco, P. Electrochemical sensors based on molecularly imprinted polymers. TrAC Trends Anal. Chem. 2004, 23, 36-48. [CrossRef]

12. Figueiredo, E.C.; Dias, A.C.B.; Arruda, M.A.Z. Impressão molecular: Uma estratégia promissora na elaboração de matrizes para a liberação controlada de fármacos. Rev. Bras. Cienc. Farm. 2008, 44, 361-375. [CrossRef]

13. Andersson, L.I. Efficient sample pre-concentration of bupivacaine from human plasma by solid-phase extraction on molecularly imprinted polymers. Analyst 2000, 125, 1515-1517. [CrossRef] [PubMed]

14. Cutter, G.A.; Oatts, T.J. Determination of dissolved sulfide and sedimentary sulfur speciation using gas chromatography-photoionization detection. Anal. Chem. 1987, 59, 717-721. [CrossRef]

15. Hwang, C.C.; Lee, W.C. Chromatographic characteristics of cholesterol-imprinted polymers prepared by covalent and non-covalent imprinting methods. J. Chromatogr. B 2002, 962, 69-78. [CrossRef]

16. Nilsson, K.; Lindell, J.; Norrlöw, O.; Sellergren, B. Imprinted polymers as antibody mimetics and new affinity gels for selective separations in capillary electrophoresis. J. Chromatogr. B 1994, 680, 57-61. [CrossRef]

17. Suedee, R.; Saelim, J.; Thavornpibulbut, T.; Srichana, T. Chiral determination of various adrenergic drugs by thin-layer chromatography using molecularly imprinted chiral stationary phases prepared with $\alpha$-agonists. Analyst 1999, 124, 1003-1009. [CrossRef] [PubMed]

18. Günther, A.; Bilitewski, U. Characterisation of inhibitors of acetylcholinesterase by an automated amperometric flow-injection system. Anal. Chim. Acta 1995, 300, 117-125. [CrossRef]

19. Ebarvia, B.S.; Ubando, I.E.; Sevilla, F.B., III. Biomimetic piezoelectric quartz crystal sensor with chloramphenicol-imprinted polymer sensing layer. Talanta 2015, 144, 1260-1265. [CrossRef] [PubMed]

20. Gu, Y.; Yan, X.; Li, C.; Zheng, B.; Li, Y.; Liu, W.; Zhang, Z.; Yang, M. Biomimetic sensor based on molecularly imprinted polymer with nitroreductase-like activity for metronidazole detection. Biosens. Bioelectron. 2016, 77, 393-399. [CrossRef] [PubMed]

21. Hosseini, M.R.M.; Motaharian, A. Electroanalytical determination of diazepam in tablet and human serum samples using a multiwalled carbon nanotube embedded molecularly imprinted polymer-modified carbon paste electrode. RSC Advances 2015, 5, 81650-81659. [CrossRef]

22. Gohary, N.A.; Madbouly, A.; Nashar, R.M.; Mizaikoff, B. Synthesis and application of a molecularly imprinted polymer for the voltammetric determination of famciclovir. Biosens. Bioelectron. 2015, 65, 108-114. [CrossRef] [PubMed]

23. Moraes, F.C. Carbon Nanotubes in Development of Electrochemical Sensors. Ph.D. Thesis, Centro de Ciências Exatas e Tecnologia, Universidade Federal de São Carlos, São Carlos, Brazil, 2010.

24. Herbst, M.H.; Rocco, A.M.; Macêdo, M.I.F. Tecnologia dos nanotubos de carbono: Tendências e perspectivas de uma área multidisciplinar. Quim. Nova 2004, 27, 986-992. [CrossRef] 
25. Bortolotto, L.A.; Consolim-Colombo, F.M. Betabloqueadores adrenérgicos. Rev. Bras. Hipertens. 2009, 16, 215-220.

26. Firmida, C.C.; Mesquita, E.T. O paradox do tratamento da ICC com betabloqueadores. Implicações para pacienteshipertensos. Rev. Bras. Hipertens. 2001, 8, 458-465.

27. Lanzanova, F.A. CArvedilol-Studies of stability and dissolution profile. Masters dissertation, Centro de Ciências da Saúde, Universidade Federal de Santa Maria, Santa Maria, Brazil, 2007.

28. Belal, T.S.; Shaalan, R.A.; El Yazbi, F.A.; Elonsy, S.M. Validated Stability-Indicating HPLC-DAD Determination of the Antihypertensive Binary Mixture of Carvedilol and Hydrochlorothiazide in Tablet Dosage Forms. Chromatographia 2013, 76, 1707-1720. [CrossRef]

29. Borda, P.A.A.; Riekes, M.K.; Pereira, R.N.; Stulzer, H.K.; Vecchia, D.D. Development and validation of a UV spectrophotometric method to quantify carvedilol. Quim. Nova 2013, 36, 582-586.

30. Hancu, G.; Cârje, A.; Iuga, I.; Fulop, I.; Szabó, Z.I. Cyclodextrine screening for the chiral separation of carvedilol by capillary electrophoresis. Iran. J. Pharm. Res. 2015, 14, 425-433. [PubMed]

31. Tarley, C.R.T.; Kubota, L.T. Molecularly-imprinted solid phase extraction of catechol from aqueous effluents for its selective determination by differential pulse voltammetry. Anal. Chim. Acta 2005, 548, 11-19. [CrossRef]

32. De Oliveira, F.M.; Segatelli, M.G.; Tarley, C.R.T. Hybrid molecularly imprinted poly(methacrylic acid-TRIM)-silica chemically modified with (3-glycidyloxypropyl)trimethoxysilane for the extraction of folic acid in aqueous medium. Mat. Sci. Eng. C 2016, 59, 643-651. [CrossRef] [PubMed]

33. Corazza, M.Z.; Ribeiro, E.S.; Segatelli, M.G.; Tarley, C.R.T. Study of cross-linked poly(methacrylic acid) and polyvinylimidazole as selective adsorbents for on-line preconcentration and redox speciation of chromium with flame atomic absorption spectrometry determination. Microchem. J. 2014, 117, 18-26. [CrossRef]

34. Dogan, B.; Ozkan, S.A. Electrochemical Behavior of Carvedilol and Its Adsorptive Stripping Determination in Dosage Forms and Biological Fluids. Electroanalysis 2005, 17, 2074-2083. [CrossRef]

35. Rofouei, M.K.; Khoshsafar, H.; Kalbasi, R.J.; Bagheri, H. A sensitive electrochemical sensor for the determination of carvedilol based on a modified glassy carbon electrode with ordered mesoporous carbon. RSC Adv. 2016, 6, 13160-13167. [CrossRef]

36. Oliveira, U.M.F.; Lichtig, J.; Masini, J.C. Evaluation of a Nafion Coated Glassy Carbon Electrode for Determination of Paraquat by Differential Pulse Voltammetry. J. Braz. Chem. Soc. 2004, 15, 735-741. [CrossRef]

37. Pinheiro, S.C.L.; Junior, I.M.R. Uso de Membranas de Nafion para a Construção de Sensores Ópticos para Medidas de pH. Quim. Nova 2005, 28, 932-936. [CrossRef]

38. Laviron, E.L.; Roullier, C.D.; Degrand, J. A multilayer model for the study of space distributed redox modified electrodes: Part II. Theory and application of linear potential sweep voltammetry for a simple reaction. J. Electroanal. Chem. 1980, 112, 11-23. [CrossRef]

39. ICH, Validation of Analytical Procedures: Methodology, Technical Requirements for the Registration of Pharmaceuticals for Human Use. Available oneline: http://www.ich.org/fileadmin/Public_Web_Site/ICH_ Products/Guidelines/Quality/Q2_R1/Step4/Q2_R1_Guideline.pdf (accessed 26 November 2016).

40. Soleymanpour, A.; Ghasemian, M. Chemically modified carbon paste sensor for the potentiometric determination of carvedilol in pharmaceutical and biological media. Measurement 2015, 59, 14-20. [CrossRef]

(C) 2016 by the authors; licensee MDPI, Basel, Switzerland. This article is an open access article distributed under the terms and conditions of the Creative Commons Attribution (CC-BY) license (http://creativecommons.org/licenses/by/4.0/). 